\title{
Commentary \\ Recently published papers: predictors, pressors and poietins
} Suzannah Ward and Richard Venn

\author{
Department of Critical Care, Worthing General Hospital, Worthing, UK
}

Corresponding author: Suzie Ward, suzieward@doctors.org.uk

Published: 21 December 2007

Critical Care 2007, 11:181 (doi:10.1186/cc6188)

This article is online at http://ccforum.com/content/11/6/181

(C) 2007 BioMed Central Ltd

\begin{abstract}
Simple, sensitive and specific predictors of mortality in the critically ill remain elusive goals, and brain natriuretic peptide and venous lactate are the subjects of recent studies. The role of vasopressin in sepsis continues to be the focus of much research interest. Dose ranging studies, potential adverse effects, and selective V1 agonists are discussed below in recent trials. Finally the use of erythropoietin in the critically ill continues to be studied but many continue to urge caution for widespread use outside of clinical trials.
\end{abstract}

\section{Predictors}

The search for simple, sensitive and specific prognostic tools in the critically ill population continues in the current literature. Brain natriuretic peptide (BNP) has emerged during recent years as a helpful tool in patients with cardiac failure, sepsis and acute myocardial infarction (MI) [1]. Meyer et al. investigated the prognostic impact of plasma $\mathrm{N}$-terminal proB-type natriuretic peptide (BNP) in an unselected cohort of 289 critically ill patients on admission to the intensive care unit (ICU) [2].

ICU and hospital survivors had significantly lower BNP when compared to non survivors (ICU BNP levels 3,394 versus $6,776 \mathrm{pg} / \mathrm{mL}$, hospital BNP levels 2,656 versus $8,390 \mathrm{pg} / \mathrm{mL}$, $p<0.001)$. There were no significant differences in BNP values between those patients with a primary cardiac diagnosis compared to those with a non cardiac diagnosis. A logistic regression model showed that Simplified Acute Physiology Score (SAPS) and BNP were independently associated $(p<0.008)$. The authors concluded that BNP may facilitate triage in the critically ill.

Howell et al. looked at the prognostic power of a single presenting venous lactate and 28 day in-hospital mortality [3]. 1,287 patients who presented to the accident and emergency unit (A\&E) with clinically suspected infection had a single venous lactate measured. Lactate levels were strongly associated with mortality even when stratified by arterial blood pressure $(p<0.0001)$. Normotensive patients with a lactate $>4 \mathrm{mmol} / \mathrm{L}$ had a $15 \%$ mortality, and overall those patients with either a diagnosis of septic shock or a lactate $>4$ had a mortality of $28 \%$. In the absence of either septic shock or a raised lactate the mortality was only $2.5 \%$. Lactate therefore has a significant prognostic value independent of arterial pressure, and this study adds to other work which has questioned the usefulness of blood pressure in early warning scoring systems [4]. Raised lactate levels allow early identification and therefore intervention in those patients at high risk of death.

\section{Pressors}

Despite the myriad of trials investigating arginine vasopressin (AVP) in the critically ill, its usefulness remains unclear. Concerns have been raised over the possible side effects including ischaemia of the mesentery, myocardium or peripheries.

A poster presentation by Rehberg et al. compared the effects of AVP and terlipressin (TP) on mesenteric blood flow and mortality in established ovine sepsis [5]. In this septic shock model, ewes were randomised to AVP, TP, or control, and all groups were given norephinephrine (NADR) to maintain mean arterial pressure (MAP) $>70 \mathrm{mmHg}$. Mesenteric blood flow was not affected by the administration of AVP or TP and systemic haemodynamic parameters recovered better in the AVP and TP groups. It is therefore reassuring that mesenteric ischaemia was not a problem in this septic model.

Landry et al. [6] have previously shown that NADR levels increase whilst AVP levels decrease in septic shock, which may explain why AVP replacement may improve haemodynamic status. Barrett et al. have explored changes in

$\mathrm{BNP}=$ brain natriuretic peptide; $\mathrm{MI}=$ myocardial infarction; $\mathrm{ICU}=$ intensive care unit; SAPS $=$ Simplified Acute Physiology Score; A\&E $=$ accident and emergency unit; AVP = arginine vasopressin; TP = terlipressin; NADR = norephinephrine; MAP = mean arterial pressure; VASST = Vasopressin in Septic Shock Trial; TESST = Terlipressin in Septic Shock Trial; EPO = erythropoietin; TRICC = Transfusion Requirements in Critical Care; MAXIMA = Maintenance of Haemoglobin Excels in Intravenous Administration of CERA. 
vascular responsiveness to AVP and the selective V1 agonist, $\mathrm{F}-180$, in a long-term rodent model of sepsis [7]. Ex vivo vascular reactivity is attenuated by NADR but increased with AVP and to an even greater extent with F-180. The implication is that the desired pressor response may be specifically V1 mediated and therefore this should be where future work in the critically ill patient should be focused.

A poster presentation by Traber et al. has also investigated a selective V1 agonist FE 202158 [8]. The $20 \mathrm{mmHg}$ drop in MAP and 50\% reduction in systemic vascular resistance in their experimental model of septic shock was only partially reversed with AVP but completely returned to pre-septic levels with FE 202158. The septic control group accumulated seven litres of fluid in 24 hours, as a probable consequence of leaking capillaries. This fluid accumulation was reduced by $50 \%$ in the AVP group and completely prevented by the selective V1 agonist, FE 202158. However in the latter group, the full prevention of this fluid and protein leakage was reduced by $50 \%$, by infusion of V2 agonist desmopressin. The fluid accumulation findings suggest that vasopressin, and in particular $\mathrm{V} 1$ receptors, play some direct role in preventing vascular leak syndrome.

We eagerly await the published, peer-reviewed results of current clinical trials on vasopressin in septic shock (VASST) and terlipressin in septic shock (TESST), to determine if these 'bench' findings translate to the 'bedside'.

The most effective dose of AVP is also unclear and Luckner et al. have performed a dose finding study comparing 0.03 with $0.067 \mathrm{IU} / \mathrm{min}$ of AVP infusions in addition to NADR (mean dose $1.07 \mathrm{mcgs} / \mathrm{kg} / \mathrm{min}$ ) in 78 patients with advanced vasodilatory shock [9]. Efficacy of treatment was determined by increases in MAP and extent of NADR reduction. MAP was higher $(p<0.001)$, and NADR requirements were reduced in the higher infusion group $(p>0.001)$. In addition lactate remained higher in the lower infusion group suggesting that the higher dose was more effective in reversing hypotension in sepsis.

\section{Poietins}

The increasing attempts to minimise the amount of allogeneic transfusions due to both its potential risks and limitations as a resource [10] has brought about an increasing enthusiasm for other alternatives including the use of erythropoietin (EPO).

The EPO Critical Care Trial Group have extended research previously involving mainly renal and oncology patients. Two studies in critical care patients have previously observed a reduction in requirement for blood transfusion [11,12], with a suggestion that trauma patients may benefit further.

The EPO Critical Care Trial Group carried out a prospective, randomised, double blinded, placebo-controlled, multicentre study which recruited 1,460 medical and surgical patients between 48-96 hours after admission to ICU. Patients at high risk of thrombosis were excluded [13]. The treatment group received EPO 40,000 U s/c once a week for three weeks, if $\mathrm{Hb}<12 \mathrm{~g} / \mathrm{dl}$.

The primary endpoint result showed no reduction in transfusion ( $46 \%$ versus $48 \% p=0.34$ ), a moderate increase in $\mathrm{Hb}$ at day 29 in the EPO group and a lower overall 29 day mortality for EPO (8.5\% versus $11.4 \% p=0.02)$. This reduction in mortality extended to 140 days in the subgroup of trauma patients $(6.0 \%$ versus $9.26 \% p=0.04$, adjusted hazard ratio $0.4,95 \% \mathrm{Cl} 0.23-0.69)$.

The EPO group had an increased number of thrombotic events $(16.5 \%$ versus $11.5 \% p=0.008)$ despite receiving only one to three doses, although the authors suggested that post hoc analysis showed that this was not significant in patients who had received prophylactic heparin.

The authors observed that the surprise lack of reduction in transfusions may be the result of the general adoption of a restrictive strategy following the Transfusion Requirements in Critical Care (TRICC) study [14]. The unexpected mortality benefit despite no drop in transfusion may be accounted for by protective nonhaemopoietic effects of EPO.

A recent meta analysis by Zarychanski et al. showed that EPO had no statistical impact on overall mortality, length of stay or duration of mechanical ventilation, but did show that EPO reduced the chance of receiving a blood transfusion. [15] The lack of effect on mortality may reflect the heterogeneity of clinical trials examined in this meta-analysis, with no controls for differing EPO doses, length of treatment and so on.

It remains important to pursue ways of minimising transfusions and the EPO agonists may indeed play a crucial part. The potential of other EPO agonists was recently highlighted in The Lancet with the use of Mircera (Maintenance of Haemoglobin Excels in Intravenous Administration of CERA [MAXIMA] study) [16].

Although there may be a real reduction in mortality in trauma patients with EPO, this requires further investigation with appropriately powered trauma specific studies. We must continue therefore to exercise caution with EPO use in the critically ill, a message reinforced by other editorialists [17].

\section{Competing interests}

The authors declare that they have no competing interests.

\section{References}

1. Burke MA, Cotts WG: Interpretation of B-type natriuretic peptide in cardiac disease and other comorbid conditions. Heart Fail Rev 2007, 12:23-36

2. Meyer B, Huelsmann M, Wexberg P, Karth GD, Berger R, Moertl D, Szekeres T, Pacher R, Heinz G: N-terminal pro-B-type natriuretic peptide is an independent predictor of outcome in an unselected cohort of critically ill patients. Crit Care Med 2007, 
35:2268-2274

3. Howell M, Donnino M, Clardy P, Talmor D, Shapiro N: Occult hypoperfusion and mortality in patients with suspected infection. Intensive Care Med 2007, 33:1892-1899

4. Hucker T, Mitchell G, Blake L, Cheek E, Bewick V, Grocutt M, Forni L, Venn R: Identifying the sick: can biochemical measurements be used to aid decision making on presentation to A\&E departments. Br J Anaesth 2005, 94:735-741

5. Rehberg S, Ertmer C, Lange M, Morelli A, Van Aken H, Westphal $\mathrm{M}$ : Effects of vasopressin and terlipressin in ovine septic shock on mesenteric blood flow and survival. Crit Care 2007, Suppl 4:P19

6. Landry D, Levin H, Gallant E, Ashton R, Seo S, D'Alessandro D, $\mathrm{Oz} \mathrm{M}$, Oliver J: Vasopressin deficiency contributes to vasodilation of septic shock. Circulation 1997, 95:1122-1125

7. Barrett L, Orie N, Taylor V, Stidwill R, Clapp L, Singer M: Differential effects of AVP and NADR on vascular responsiveness in long term rodent model of sepsis. Crit Care Med 2007, 35:2337-2343

8. Traber D: Selective V1a agonists in experimental septic shock. Crit Care 2007, Suppl 4:P51

9. Luckner G, Mayr V, Jochberger S, Wenzel V, Ulmer H, Hasibeder W, Dünser M: Comparison of 2 dose regimens of AVP in advanced vasdilatory shock. Crit Care Med 2007, 10:22802286

10. Stainsby D, Cohen $\mathrm{H}$, Jones $\mathrm{H}$, Boncinelli A, Knowles S, Birchall J, Chapman C, Milkins C, Davison K, Brant L, Gray A, Standard Working Group: SHOT report 2005.

11. Corwin H, Gettinger A, Rodriguez RM, Pearl RG, Gubler KD, Enny C, Colton T, Corwin MJ: Efficacy of recombinant human erythropoietin in the critically ill patient. Crit Care Med 1999, 27:2346-2350

12. Corwin HL, Gettinger A, Pearl RG, Fink MP,Levy MM, Shapiro MJ, Corwin MJ, Colton T: Efficacy of recombinant human erythropoietin in the critically ill patient. JAMA 2002, 288:2827-2836

13. Corwin HL, Gettinger A, Fabian TC, May A, Pearl RG, Heard S, An R, Bowers PJ, Burton P, Klausner MA, Corwin MJ: Efficacy and safety of epoetin alfa in critically ill patients. $N$ Engl J Med 2007, 357:965-976

14. Hebert PC, Wells G, Blajchman MA, Marshall J, Martin C, Pagliarello G, Tweeddale M, Schweitzer I, Yetisir E: Transfusion Requirements In Critical Care Investigators $N$ Engl J Med 1999, 340:409-417

15. Zarychanski R, Turgeon AF, Mclntyre L, Fergusson DA: Erythropoetin- receptor agonists in critically ill patients: a metaanalysis of RCTs. CMAJ 2007, 117:715-734

16. Levin NW, Fishbane S, Valdes Canedo F, Zeig S, Nassar G, Moran JE, Villa G, Beyer U, Oquey D: Intravenous methoxy polyethylene glycol epoetin beta for haemoglobin control in patients with chronic kidney disease on dialysis Lancet 2007, 370:1415-1424

17. Cook D, Crowther M: Targeting anaemia with erythropoetin during critical illness N Engl J Med 2007, 257:1037-1039 